\title{
Intellectual Property in Clinical Research - the Obstacles on the Road
}

\section{Iulianna LUPASCO*}

\begin{abstract}
Intellectual property behind the scenery of clinical research present a very special issue in scientific field presenting a deep underestimation of the main precious production of scientific researchers - production of mind, intellect, knowledge, clinical practice and research. In this article are highlighted main questions the young researches and not only young ones face while generating ideas, developing into nice projects. In this topic are discussed the main types of intellectual property in clinical research with a short introduction how the law protects them on a national level and why intellectual property is important for every clinical scientist. The literature review is closely intertwined with our own observations over the years in terms of intellectual property. Finally, the main benefits of intellectual property protection for clinical researchers will be presented empowering with new contacts and scientific innovation leaders from other places of the world.
\end{abstract}

Keywords. Intellectual property, clinical research.

JEL Code: 119

\section{Introduction}

The idea of discussing this topic from behind the scenery of clinical researcher burst out not so spontaneously, but grew up slowly, due to many years of working in scientific field and struggling with deep underestimation of

\footnotetext{
* Iulianna LUPASCO is university associate professor at "Nicolae Testemitanu" State University of Medicine and Pharmacy, Chisinau, Moldova. E-mail: labgastroenterologie@usmf.md
} 
the main precious production of my colleagues - production of their mind, intellect, knowledge, clinical practice and research. In this article I would love to share some issues the young researches and not only young ones face while generating ideas, developing into nice projects, meeting plagiarism and sometimes even stolen accumulated data. In the modern scientific world, we constantly hear about the need to present inventions most often: during the master or PhD process; during clinical trials with or without pharmaceutical remedies; during the application process for receiving a financial grant; during annual and especially final completion reporting of a scientific project;

Moreover, most often the young scientists do not understand why there is a need to whatever IP elaboration and treat it as a cruel necessity that takes time form there research. After all, many of them do not at all strive to protect their intellectual property.

When we start describing the Intellectual property (IP) we need to understand the main meaning of it:

IP refers to creations of the mind - everything from works of art to inventions, computer programs to trademarks and other commercial signs (wipo, 2020).

In this article, we shall discuss:

- The main meaning of IP.

- Variants of possible IP in clinical research.

- We shall go notice at a glance some laws behind the IP.

- A short excurse into what was done so far on the country level for medical students and researchers.

- In conclusion the reasons why IP is important for clinical scientist.

\section{Importance of intellectual property in clinical research: questions and} answers.

\subsection{The main meaning of intellectual property.}

Therefore, going further, on the IP road, in a Geoff Tansey article it is possible to find the very nice and understandable description of different types of intellectual property: 
These different forms provide creators and inventors with legal protection from someone copying or using their work or invention without permission. Some protect the intellectual knowledge behind technological innovations (patents) and others protect creative works such as books, films and music (copyright). (Tansey, 2006, p.2)

But if we try to understand what specialists say, from philosophical "bird view" the "Intellectual property is a twentieth-century generic term used to refer to a group of legal regimes which began their existence independently of each other and at different times in different places" (Drahos, 1996, p.14). Moreover, this is true nowadays as well, because every country has a bunch of specific laws consolidating basis of IP protection in somehow different manner from other countries in which way they define economic aims and the legal rights of patent holders to intellectual property. Moldova, of course, has the legislative base of IP, as other European countries, having the special state bodies in this field (craneip.com, 2021). Therefore, from here the fog of understanding the main meaning of IP starts to disappear and arise other issues. Before starting the topic of discussion about what types of IP are generated most often by scientists in clinical trials, one should dwell on what scientists face when they hear about IP. Lack of understanding what this IP actually means from practical point of view lead, accordingly, to appearance of this kind of questions:

- Why there is a need to draw up some kind of paper?

- What types of IP exist? and

- What can be protected in this case during a clinical trial?

- What is "a transfer of technology" and how it can be related to the clinic?

- What is "an implementation" and why are scientists so persistently required to show that it was carried out in the course of the study?

The main issue of scientist is intellectual productivity. The main goal is to protect this intellectual output. So the intellectual property system needs to balance the rights and interests of different groups: of creators and consumers (wipo, 2020).

Medical research faces many different problems:

- Elaborating new pathways of diagnosing based on clinical studies, 
- Evaluation new medication targets and agents in treating different diseases,

- Creating specific algorithms, as well as national clinic protocols, guidelines of treatment and monitoring a broad spectrum of medical conditions, etc.,

- Establishing of novel prophylactic measures on local, national or even international level.

Most of clinical research projects supervisors are focused on technical issues and material substance of intellectual property, but protection of science ideas, protocols, guidelines, monographs, $\mathrm{PhD}$ theses, etc. matters not less, but sometimes even more for the science community and public health on a country level. At the same time, the idea of scientific research is the most valuable core of any project, since without it, there is impossible to build whatever skeleton and structure and, in fact, to implement, just because simple nothing will be to implement. No idea is born out of thin air; it is preceded by long hours of studying scientific material on the relevant topic. Now, after some kind of eureka, an idea is born, formed, structured and voiced. However, as soon as she flies out into the world, she no longer belongs to the author; she has a life of her own (Figure 1).

This is the place where the researcher should be careful, since the study of the idea in a scientific sense, confirmation by appropriate tests, analyzes and so on, the publication of personal data obtained, in no way fully protect intellectual rights. In addition, here lies the core stone of the discussion - IP is the legal protection of your product.

From other hand we have to remember that clinical researches serve public health and have to be used worldwide as it is clearly defines Taubman Antony "The struggle to combat human disease and to promote health is inherently international in character and is recognized as an element of maintaining international peace and security" (Taubman A, 2008, p.526)

During our daily struggling in fulfilling the aims and criteria of the ongoing clinical research (CR) we need to focus on another basic thing - about the importance of this work -importance of the scientific work on the field of public wealth improvement. 


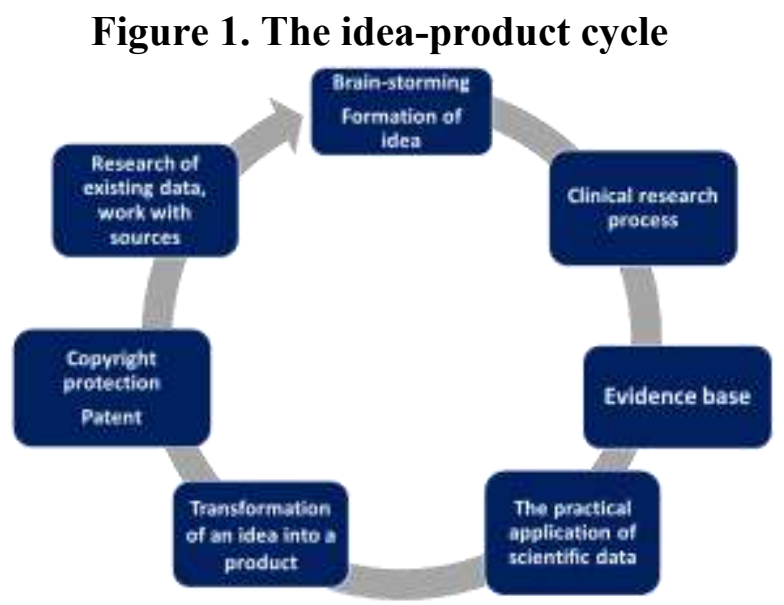

Source. Elaborated by author.

Clinical research are under careful attention due to

A) The important role that it plays in public health, by developing new strategies in diagnosing and treatment of diseases.

B) The human participant's evaluation.

C) The researchers' dependence on the scientific outcome, based on statistical data to create some new medical recommendations, because without statistical significance, all conclusion are still remain theories.

D) The financial funding by State, or other grants supporting the research group and necessary equipment, so it is money that lay in between idea and product, like crème in the cake layers.

In addition, here the logic question appear - Why it is important to apply for IP? This necessity has a dual effect as well:

- From one point of view - protection from plagiarism.

- From the other - IP guarantees consumers that the products they buy or use have been tested, approved and safe.

A counterfeit product may look exactly like the original, but has often not been tested to make sure it is safe. This is especially true for some herbal or biologic products based on authentic "original" recipes. 


\subsection{Variants of IP in clinical research.}

Let us going into differentiation of IP. There are 2 main variants of IP.

- Copyrights and related rights

- Industrial property

Copyrights give authors the right to protect their work. It covers databases, reference works, computer programs, architecture, books, technical drawings, and others. By copyrighting your work, you ensure that others cannot use it without your permission.

Industrial property rights include trademarks, patents and industrial designs. A trademark is a unique sign used to identify a product or a service. It can be a single word or a combination of words and numbers. Drawings, 3-D signs, or even symbols can constitute a trademark. For instance, "CRICOVA" is a famous national trademark with its own Registration Number 5389614 and Registration Date 2018-01-30, as well as "Floravita" oil (AGEPI, BOPI, 2017, p.102). The trademark application can be filed at national or regional levels depending on the extent of protection required. The same criteria meet medical facilities, instruments, machines and so on. For example, the well-known Moldovan-Romanian joint venturen "EUROFARMACO" has its own trademark (Figure 2) (Registru Național al Cererii, 2021).

Figure 2. The EUROFARMACO trademark

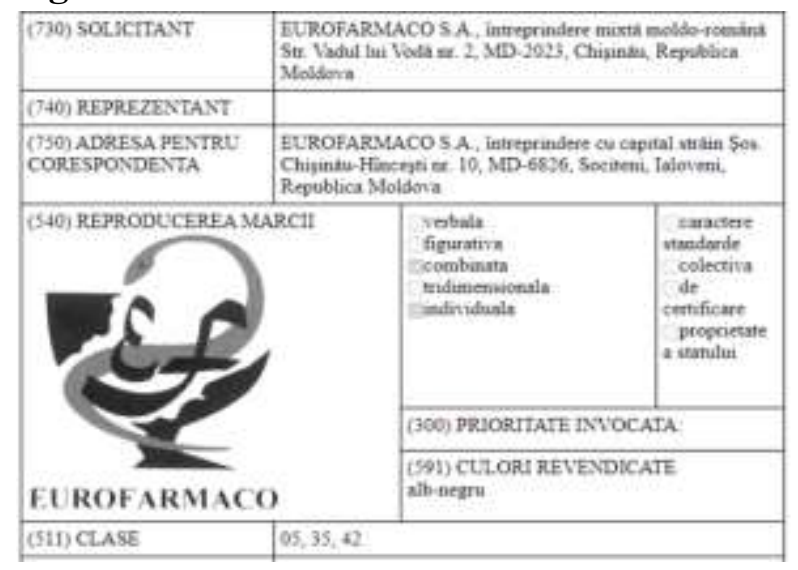

Source. Registru National. Cereri de inregistrare a marcilor. http://db.agepi.md/trademarks/RegistruCererii?id=13ef0841d7374e4b975fcc6 4f7658e6a 
The possibility is large for developing the IP starting from the manufactures and finishing with a product, such as a medication "XILOZIN", or "XILOZIN P" that serve as a nazal remedies for decongestion for topical usage, a sympathomimetic (AGEPI, 2017, p.78).

Geography in IP trademark, does it matters? A geographical indication states that a product belongs to a specific region and has quality or reputation owing to that region. Here are some examples:

- Palinca or Pálinka (Hungarian: Pálinka) is a traditional alcoholic beverage from Hungary and Romania, with a high alcohol content (52\% legal percentage).

- "Palinca de Maramures" is a brand of traditional Romanian spirits from Maramures county. It is a product with a protected geographical name and recognized in Romania for spirits, as well as "Palinca de Bihor" (Ordin nr.147, 2005).

Rooibos tea, Basmati rice are other well-known products with geographic IP. Can we find the same possibility in medical frame? If someone consider that in medicine there is no place for a trademark, this is wrong.

- $\quad$ A Red Cross trademark, Red Cross logo and Red Cross brand present symbols of Red Cross organization worldwide, serve as official labels for the Red Cross nonprofit company and are under IP protection.

- $\quad$ And another variant connected with this topic: American Red Cross Philippine - a trademark with a geographical indication (Figure 3).

Figure 3. A Red Cross and American Red Cross Philippine trademarks
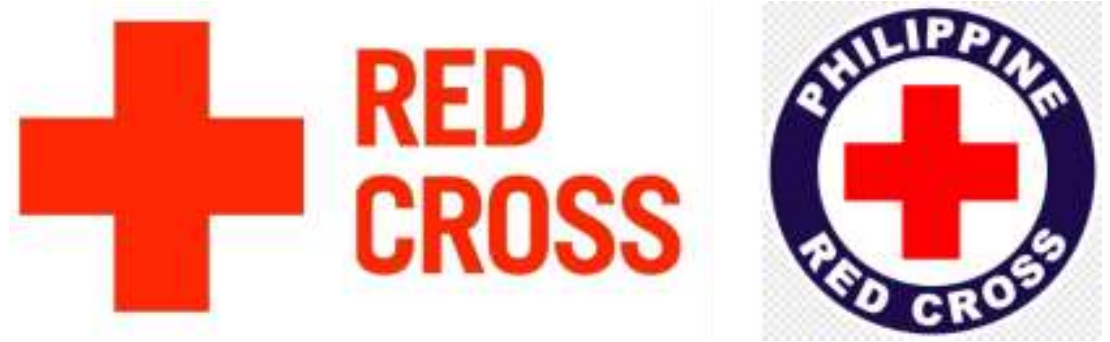

Source. Internet page with Red Cross trademark http://logosign.com/tag/red-cross-trademark/ and https://www.pngegg.com/en/png-saizh 
This worldwide trademark is under very strong protection according the Charter Act adopted by Congress in 1900 in connection with the Geneva Convention 1960 Chapter 4, Article 12 (and later amended in 1905 and 1910), so the American Red Cross has the exclusive right to use a red, Greek cross on a white field (GENEVA CONVENTIONS ACT, 1960, p.6)

Another type of IP is an industrial design a document that makes a product unique, attractive and useful. These may include 3-D (shape or surface of an object) or 2-D (lines or patterns) features. An "industrial design" phrase has a kind of an ice-machine sense to clinician that doubtly could be used in clinical research, but actually, it does. The shape of a bottle, plastic or metal equipment and so on could serve as examples of the industrial design.

An example from 2017 BOPI magazine is a portable monitoring device of vital bio signals (AGEPI, 2017, p. 126) (Figure 4).

\section{Figure 4. An industrial design of the portable monitoring device of vital bio signals}
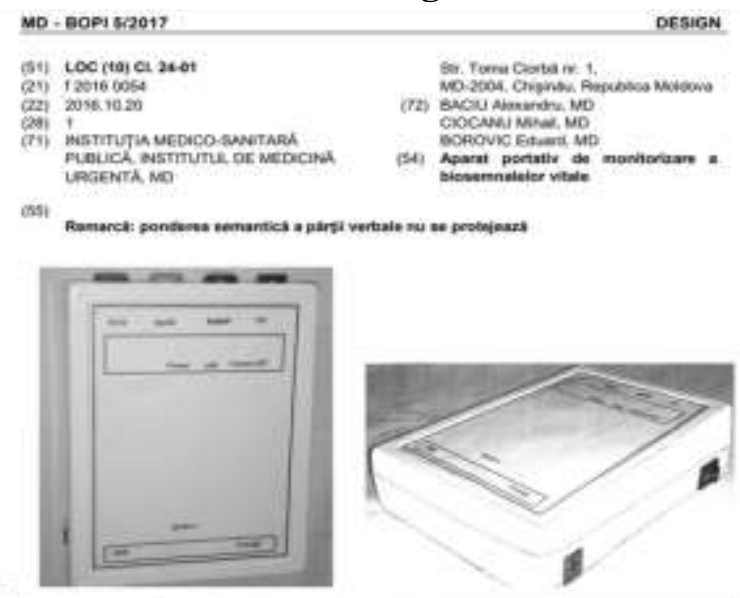

Source. BOPI magazine, 2017, p. 126. 
A patent is another kind of IP and gives an exclusive right to an invention that introduces a new solution or a technique. If the researcher is a patent owner, he/she is the only person who can manufacture, distribute, sell, or commercially use that product, if. If all the documents are perfectly correct. Moreover, the document filing is a specific process and here is a place, where researches need a hand of specialists in IP masterpiece. Why? Firstly due to the timeline of its life (patents are usually granted for a period of 20 years). Secondly, because the more professional specialist helps the researcher in the process of patent development, the better protection it receives in the end. The example for this can serve the JSC "Laboratorios Menarini" lawsuit against SRL "Balkan Pharmaceuticals", basing on the fact that the defendant violated the rights of the deriving from patent no. MD 921 from 31.10.1998 approved by the Government. After a very careful evaluating process of the materials of the case, the court came up with a decision that the invention proposed and invoked by the JSC "Laboratorios Menarini" did not meet the conditions of patentability and did not have an inventive character. Consequently, according to the law there was a cancelation of the existed patent no. 921 of an applicant JSC "Laboratorios Menarini".

So from here we receive a message from the mentioned above that "The state registration of the works protected by copyright and related rights" shall be performed by AGEPI specialists in accordance with the regulation of Law (LAW No. 139, 2010).

A special attention has to be paid for a copyright discussion. (C) - copyright protection mark, represented by the Latin letter $\mathrm{C}$ (the first letter of the word "copyright"), placed in the center of the circle. Do we use it consciously every time? Not so, but in case of a team work with other specialists the mark appears on the final version of printed material. What does it mean? The copyright mark is used with the name of the person or entity that owns the copyright. The object of copyright protection can also be indicated, as well as the year of publication. 
Figure 5. A copyright mark and an example on the printed Abstract book for the PhD theses
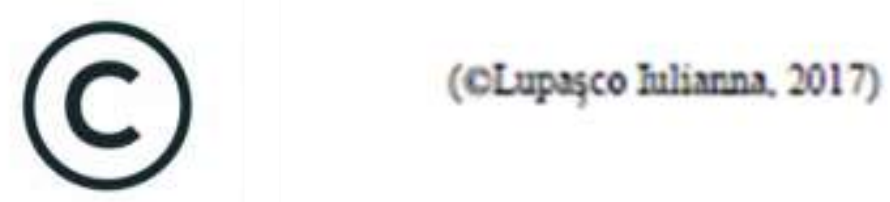

Source. Elaborated by author, based on the existed copyright mark and authors' own printed material (Lupasco, Iu, 2017).

\subsection{Some laws behind the intellectual property.}

The copyright law of Moldova regulates the copyright of residence in our country. The first official decree related to copyright in the country was made on 25 November 1991, shortly after its independence on 27 August of the same year. After creating the State Agency for Intellectual Property (AGEPI), finally, Moldova replaced the 1994 law with a new one in 2011y. The European Union (EU) participated in its drafting to help the country have laws compatible with the most important international copyright treaties. The exceptional broad review on this topic was done by Jose Maria Gil-Robles during the Jean Monnet Conference "The development of intellectual property in the EU and Moldova: challenges and perspectives" held on 12 of March 2021 in Chisinau, Moldova. It is impossible not to mention the main idea reflected in Article 5 "Conditions of protection" of the 2010 copyright law:

- (1) In accordance with this law, all works expressed in a certain objective form in the literary, artistic and scientific field shall benefit from protection, regardless of whether or not they have been brought to the public's attention.

- (2) The author benefits from the protection of the copyright over his work by the very fact of its creation. For the appearance and exercise of copyright, it is not necessary to register the work, nor any other act of notification or other formalities. (LAW No. 139, 2010, p.7)

Moreover, what is extremely important : 
"(6) Copyright protection extends to the form of expression, but does not extend to ideas, theories, scientific discoveries, procedures, methods of operation or mathematical concepts as such, nor to inventions contained in a work, whatever the way of taking over, explaining or expressing." (LAW No. 139, 2010, p.7)

The copyright law of Moldova regulates the copyright of residence in our country that is reflected in Article 6:

“(1) Copyright extends to:

a) works, regardless of the place of their first publication, the copyright holder of which is a natural or legal person of the Republic of Moldova;" (LAW No. 139, 2010, p.7)

So if a researcher did not put all mental thoughts on the paper list, they are not protected, but this is only the beginning of the process. And in a very similar way how we learn the medical base material it is essential to study the "main notions" reflected in Article 3 of the Law that make sense for researcher: author, database, collective work, public communication, public demonstration, distribution, publication, etc., (LAW No. 139, 2010, p.3).

Going further in the same article we can see that

(3) The copyright consists of patrimonial rights and moral rights (nonpatrimonial personal).

(4) The copyright does not depend on the property right over the material object in which the respective work found expression. The purchase of such an object does not confer on its owner any of the rights granted to the author of this law.

(5) The patrimonial rights may belong to the author or to another natural or legal person who legally holds the respective rights (the holder of rights). (LAW No. 139, 2010, p.7)

Registration is important evidence in any case of stolen creation, or even in intention to dothis, in which case an IP document can be recognized by a court as a presumption of authorship unless proven otherwise. There is a lot more in this document that gives an opportunity to understand what is valuable and enriches the brain storming process with new ideas.

So why it is so important for a clinical researcher? A researcher who wants to obtain any IP 
- Have to read more,

- Have to enrich the existed knowledge with different kind of information as well as with some law documents.

After that - to discuss the idea with an IP officer and finally to come up with a clear designed document and after a certain period of time and specific passes to receive the IP paper.

However this is not the end, as many of researchers think, this is just a beginning. Historically, two main moral and philosophical arguments for rewarding creative and innovative people have been used. One stems from the view of the nineteenth-century German philosopher Hegel postulating that an idea belongs to its creator because the idea is a manifestation of the creator's personality or self. The other approach advanced John Locke, the seventeenthcentury English philosopher by postulate that the value added through work should be rewarded with a property (Tansey, 2006). Implementation of the product "includes the translational efforts that take healthcare interventions beyond the closed systems of evaluation studies into the open systems of 'real world' contexts" according to May, C.R and coauthors. (May, Johnson \& Finch, 2016, p.1)

All scientific clinical researches are focused on improvement of clinical management of diseases, new treatment options and in this way new developed techniques, algorithms, clinical protocols while implemented in real practice serve as a final scientific product as a best benefit for public health.

If we return to the very beginning of the idea formation - the implementation is the endpoint of this process. The main mistake of clinical researchers that they actually do implement all the results, but in very rare cases obtain an IP documental approval of the implementation process (Figure 6).

\subsection{What was done so far on the country level for medical students and researchers?}

When a young investigator starts the journey in the science' cosmos a bunch of new knowledge, rules, some approaches and so on appear on the road. IP is like a hidden tree among the tropical forest, which unknown fruit is strange but sophisticated by appearance. For a better understanding and sensibilization of scientific researches of the need to protect IP in the State University of Medicine and Pharmacy named after "Nicolae Testemitanu", different training 
seminars, round tables and other activities have been held for young scientists for several years.

Figure 6. The implementation process in clinical research.

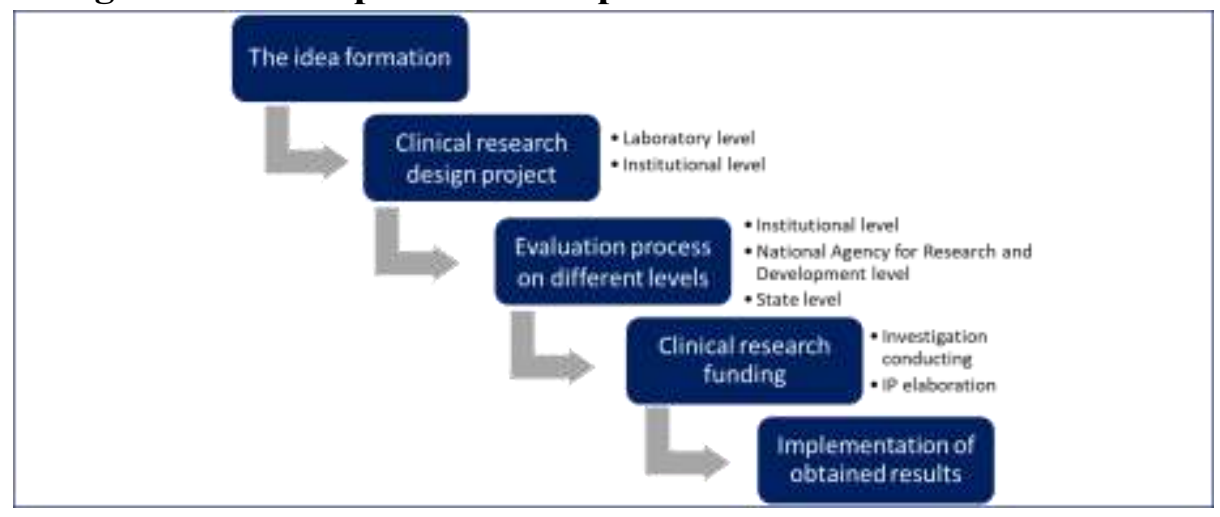

Source. Elaborated by author.

For example, talking about the targeted audience, approximately $90 \mathrm{PhD}$ students, students and professors from the "Nicolae Testemitanu" State University of Medicine and Pharmacy in 2017 participated in a training seminar entitled "Intellectual Property - a tool for capitalizing on research results", organized by the State Agency for Intellectual Property (AGEPI). The seminar aimed to familiarize participants with the national system of intellectual property protection. During the 2019 year were organized lectures "Protection of intellectual property" (inventions, copyright, etc.) and "Intellectual property as a tool for capitalizing on research results". The main targets of the events were:

- Improvement of the research skills of PhD students;

- Involvement in complex research activities;

- Adaptation to a unified and systematic approach to counteracting academic plagiarism and identifying opportunities to raise awareness against plagiarism and promote academic ethics, the peculiarities of copyright, etc.

The events were organized by the Science Department based on a collaboration agreement between AGEPI and the University. The activities 
became a part of the Advanced Research Training Program of the Doctoral School in Medical Sciences of "Nicolae Testemitanu" SUMP.

Finally, the extremely important news is that the Intellectual Property Discipline was introduced in the university curriculum; cycle III within the first year of higher doctoral studies.

The Medical Scientific Library of the "Nicolae Testemitanu" State University of Medicine and Pharmacy together with the State Agency for Intellectual Property organize an information seminar for researchers, professors and university students every year. The seminar usually is focused on the protection of intellectual property as a method of promoting products and services, encouraging technology transfer and attracting investment to continue scientific research. It covers an information about the service inventions, highlights what is the patentable object of the invention, the management of the examination procedure through the dialogue between the examiner and the applicant, etc.

Every year, in order to promote innovation in the field of medicine, the Department of Innovation, Marketing and Technology Transfer holds the "Day of Inventor and Rationalizer", which is traditionally held on the basis of "Nicolae Testemitanu" State University of Medicine and Pharmacy Medical Scientific Library.

However, the coverage of participants is more behind the scenes than wide, gathering only those who already understand the great importance of IP protection and usually call participants who are awarded for their inventions. Moreover, this is so sad, because colleagues who worked a lot on their scientific projects share their distinctive awards among the same community of patentholders, but other part of researches remains far from understanding the proud of such great appreciation on a national and especially international levels.

Traditionally, the State Agency on Intellectual Property (AGEPI) carries out various activities in order to raise awareness among researchers and inventors in the Republic of Moldova. Usually these events are about the need to protect scientific and innovative achievements, sources of information in the field of intellectual property and other aspects of ensuring the protection of intellectual property rights, as well as actions to support and promote the achievements of inventors at international exhibitions of inventions. In this 
context, it is a need to mention a very important event. Every year in our country an "International Specialized Exhibition of Intellectual Property, Creativity and Innovation" "INFOINVENT" is organized, gathering different scientists to share their inventions and many other intellectual products. The main fact is that to participate in the conference, or whatever activity you need to be an owner of IP already. Thus, the circle is closed in order to participate in the conference one have to be an owner of intellectual property or to some extent to be in a process of obtaining it.

Concluding the writing, I would love to return to the title. Obviously, there is many obstacles on the scientific road in creating the investigation protocol, evaluating of research project, accumulating and statistical processing of the obtained data, etc. An intellectual property privilege can be estimated as another obstacle on the road, but actually, it is just a new step on the accumulated knowledge pyramid. With our business rivals, we rack our brains to think of some mind-blowing new product that will make them irrelevant, and, in the process, we take our eye of the ball. We shy away from writing a book or making a film even though it's our dream because it's so much work, we can't imagine how we get from here to there.

How often do we compromise or settle because we feel that the real solution is too ambitious or outside our gasp? How often do we assume that change is impossible because it's too big? Involves too many different groups? Or worse, how many people are paralysed by all their ideas and inspirations? They chase them all and go nowhere, distracting themselves and never making headway. They're brilliant, sure, but they rarely execute... all these issues are solvable... (Holiday, R. (2014) p.110.)

So, where is the solution? The solution is closer that could be believed, it is right in our mind capacities. If we refer ourselves to scientists, we have to be ready to learn new material and go through any wall, or find the right door. From my consideration, it is a great need to maximize the information among researches that there is a very strong necessity of obtaining the IP document in clinical science. 


\section{Conclusions}

Intellectual property present in different types having the main basis of legislative issue in the core.

Intellectual property serve to protect the rights of mind production of every clinical researcher from one hand and protect the rights of patients from the other.

The obtaining intellectual property in clinical research is an important issue and needs to be estimated extremely high by every scientist.

The working process in intellectual property pretends to receive a new knowledge and takes a researcher on another level of working on the own data.

The process of obtaining an intellectual property gives a scientist an opportunity to communicate to different from the medical community people and receive another angle of view on the mind product, enriching with some new practical ideas in the course.

In Republic of Moldova exist a special legislation in the sphere of copyright and related rights that serve for protection of the author.

Some valuable special events are held on a national and international level every year in order to promote innovation in the field of science and, from my consideration, all clinical researchers must participate in them to receive a new experience.

A clinical researcher have to obtain an intellectual property in order to become a visible person in the country among patent-holders and generate new possibilities in collaboration on a interdisciplinary level.

It waves a researcher on a different arena and arises the scientific confidence on a very new level of scientific life, empowering with new contacts and scientific innovation leaders from other places of the world.

Acknowledgement: The work was carried out within the State Program (20202023) "Chronic liver and pancreatic diseases: nutritional and surgical aspects" 20.80009.8007.37. 


\section{References}

Drahos, P. (1996). A Philosophy of Intellectual Property, Aldershot, Dartmouth. Retrieved from https:/pressfiles.anu.edu.au/downloads/press/n1902/pdf/book.pdf

CRANE IP (2021). Intellectual Property Laws of Moldova and state bodies of intellectual property system. Retrieved from https://craneip.com/intellectual-property-laws-of-moldova-and-statebodies-of-intellectual-property-system

Taubman, A. (2008). The international patent system and biomedical research: reconciling aspiration, policy and practice, The American Association of Pharmaceutical scientists Journal, 10 (4), pp.526-536.

AGEPI, (2017). Buletin oficial de Proprietate intelectuală/The Official Bulletin of Intellectual Property. Chisinau. Retrieved from http://agepi.gov.md/sites/default/files/bopi/BOPI_05_2017.pdf

ORDIN nr. 147, (8 martie 2005) pentru aprobarea Listei cuprinzând denumirile geografice protejate și recunoscute în România pentru băuturi spirtoase. http://maap.ro/pages/industrie_alimentara/ORDIN\%20nr147.p

Geneva Conventions Act. (1960), N.6 of 1960, Retrieved from https://ihldatabases.icrc.org/applic/ihl/ihlnat.nsf/0/aeae4d0de5332b64c12563aa004a6f27/\$FILE/GENEVA\%20C ONVENTIONS\%20ACT,\%201960.pdf

Lupașco, I. (2017). Hepatitele cronice virale B și C la adulți (factorii de risc, particularitățile clinico-evolutive, hormonal-metabolice, imunologice și optimizarea metodelor de tratament). Autoreferatul tezei de doctor habilitat în științe medicale. Chisinau: Ericon. 49p.

May, C.R., Johnson, M., Finch, T. (2016). Implementation, context and complexity. Implementation Sci, 11(141), p.12. Retrieved from https://doi.org/10.1186/s13012-016-0506-3

Holiday, R. (2014). The obstacle is the way. The ancient art of turning adversity to advantage. London: Profile Books. 220p. ISBN: 9781781251492

Tansey, G. (April 2006). Global Rules, Patent Power and Our Food Future: Controlling the Food System in the 21st Century, IIIS Discussion Paper No. 130, pp.2-29. Retrieved from https://ssrn.com/abstract $=923771$ or http://dx.doi.org/10.2139/ssrn.923771

WIPO (2020), What is Intellectual Property. Retrieved from https://www.wipo.int/edocs/pubdocs/en/wipo_pub_450_2020.pdf 